\title{
Small Intestine Resection
}

National Cancer Institute

\section{Source}

National Cancer Institute. Small Intestine Resection. NCI Thesaurus. Code C51510.

Surgical removal of part or all of the small intestine. 